\title{
Remoção de carga orgânica recalcitrante de lixiviado de resíduos sólidos urbanos pré-tratado biologicamente por coagulação química-floculação-sedimentação
}

\section{Removing recalcitrant organic load of landfill leachate from urban solid waste pretreated biologically by coagulation-flocculation-sedimentation}

\author{
Elson Mendonça Felici \\ Engenheiro Ambiental pela Universidade Estadual Paulista "Júlio de Mesquita Filho" (UNESP). Mestre em Engenharia de Edificações e Saneamento pela \\ Universidade Estadual de Londrina (UEL) - Londrina (PR), Brasil.

\section{Emilia Kiyomi Kuroda} \\ Engenheira Civil. Doutora em Engenharia Civil. Professora adjunta da UEL - Londrina (PR), Brasil.
}

Fábio Yamashita

Engenheiro de Alimentos. Doutor em Engenharia de Alimentos. Professor associado da UEL - Londrina (PR), Brasil.

\section{Sandra Márcia Cesário Pereira da Silva}

Engenheira Civil. Doutora em Engenharia Civil. Professora associada da UEL - Londrina (PR), Brasil.

\section{Resumo}

\begin{abstract}
A utilização de pós-tratamentos físico-químicos no tratamento de lixiviados tem sido uma alternativa utilizada para a remoção da carga orgânica presente nesse efluente. Dessa forma, este artigo teve como objetivo avaliar a técnica de tratamento físico-químico pelo processo de coagulação química-floculaçãosedimentação como alternativa para pós-tratamento de lixiviado tratado biologicamente. Para isso, utilizou-se o equipamento de reatores estáticos Jarteste, e os parâmetros monitorados para avaliar a eficiência do tratamento físico-químico foram cor verdadeira e demanda química de oxigênio (DQO). Por meio da técnica de planejamento fatorial e analisando-se os resultados obtidos, pôde-se verificar que as maiores remoções de cor e de DQO foram encontradas combinando-se dosagem de $400 \mathrm{mgFe}+3 / \mathrm{L} \mathrm{com} \mathrm{pH} \mathrm{3,0,} \mathrm{alcançando-se} 98$ e $81 \%$ de remoção de cor e DQO, respectivamente.
\end{abstract}

Palavras-chave: lixiviado; coagulação-floculação; cloreto férrico; pós-tratamento.

\section{Abstract}

The utilization of physical-chemical post treatment on landfill leachate has been an option employed to remove organic compounds from this effluent. In this way, this article aimed to evaluate the physical-chemical treatment by coagulation-flocculation-sedimentation as an alternative in the post-treatment of landfill leachate submitted to biological treatment. Consequently, it was used a Jar-test to monitor true color and chemical oxygen demand (COD) in order to evaluate the efficiency of the physical-chemical treatment. By means of factorial design and analyzing the results, it was found that the best removals of color and COD were attained by combining a dosage of $400 \mathrm{mg} \mathrm{Fe}+3 / \mathrm{L}$ with $\mathrm{pH} 3.0$, achieving 98 and $81 \%$ of color removal and COD, respectively.

Keywords: landfill leachate; coagulation-flocculation; ferric chloride; post treatment. 


\section{Introdução}

Uma das alternativas para a disposição dos resíduos sólidos são os aterros sanitários. Contudo, a degradação dos resíduos aterrados gera subprodutos que podem ser nocivos ao meio ambiente, como, por exemplo, o gás metano e o lixiviado.

O lixiviado caracteriza-se pelo alto potencial de contaminação, podendo atingir o solo, as águas superficiais e subterrâneas. Além disso, possui composição variada, a qual depende da idade do aterro sanitário, do grau de estabilização do material sólido, das características do material aterrado e do regime de chuvas (CASTILHOS JR, 2006). Em geral, apresenta como características altas concentrações de $\mathrm{N}$-amoniacal, de matéria orgânica e de compostos orgânicos de difícil degradação, como as substâncias húmicas e fúlvicas. Contudo, diversos estudos têm demonstrado que o tratamento por lodo ativado em batelada, precedido de remoção física de parte do nitrogênio amoniacal por stripping, para lixiviados de aterros mais antigos, apresenta remoção de demanda bioquímica de oxigênio (DBO) e nitrogênio superior a $80 \%$ e de compostos recalcitrantes inferior a $20 \%$ (AMOKRANE; COMEL; VERON, 1997; WISZNIOWSKI et al., 2006; ZOUBOULIS; CHAI; KATSOYIANNIS, 2004).

Nesse sentido, é interessante que essa forma de tratamento não seja utilizada sozinha, devendo sempre vir acompanhada de outras tecnologias de tratamento (OZTURK et al., 2003; WANG et al., 2002; KURNIAWAN; WAI-HUNG; CHAN, 2005), como o pós-tratamento físico-químico através de coagulação química-floculação-sedimentação, que pode ser uma alternativa para a remoção de compostos indesejáveis no efluente que não foram removidos pelo tratamento biológico, como os compostos recalcitrantes.

A eficiência da coagulação química-floculação-sedimentação depende das características do líquido a ser tratado e sofre os efeitos do tipo e da dosagem de coagulante utilizados, do pH de coagulação, do tempo e do gradiente de velocidade de mistura rápida e de floculação, entre outros (DI BERNARDO \& DANTAS, 2005).

A coagulação química é realizada geralmente com a adição de um sal à base de ferro ou alumínio. Nesta pesquisa, o coagulante utilizado foi o cloreto férrico.

\section{Objetivo}

Avaliar o processo de coagulação química-floculação-sedimentação, utilizando-se cloreto férrico como coagulante para pós-tratamento de lixiviado tratado biologicamente, visando à remoção de matéria orgânica recalcitrante, medida como demanda química de oxigênio (DQO) e cor verdadeira.

\section{Materiais e método}

O lixiviado foi coletado no aterro controlado de Londrina (PR), em operação há mais de 30 anos, por meio de caminhões-tanque devidamente preparados para evitar contaminação. Depois de coletado, esse material foi armazenado em um reservatório de 5.000 L, localizado no Laboratório de Hidráulica e Saneamento da Universidade Estadual de Londrina (UEL). Para gerar o lixiviado a ser submetido ao pós-tratamento por coagulação química-floculação-sedimentação, objeto desta pesquisa, foi necessário realizar o tratamento por arraste (stripping) para favorecer a volatilização da amônia não ionizada, pelo aumento do contato do lixiviado com o ar e lodos ativados em bateladas, que foi realizado em escala piloto, utilizando-se reservatórios de 250 L. O sistema de arraste de amônia foi empregado, devido à elevada concentração de $\mathrm{N}$-amoniacal do lixiviado coletado no aterro, , buscando favorecer o desempenho do processo biológico por lodos ativados na remoção de carga orgânica e nitrogênio.

O sistema de lodos ativados iniciava-se com a passagem do efluente do stripping para a fase aeróbia, utilizando-se insuflação de ar por compressor, para remover a matéria orgânica e o N-amoniacal através do acúmulo de nitritos, com formação mínima de nitrato, ou seja, pela via curta. Quando se observava o início da formação de nitrato, desligava-se o dispositivo de aeração e, após 30 minutos de repouso do sistema, acionava-se o revolvimento pelas pás agitadoras, com controle da rotação, para evitar a aeração do líquido, adicionando-se etanol como fonte externa de carbono, a fim de que ocorresse o processo de desnitrificação.

Ressalta-se que, ao iniciar a fase de aeração, já em outro reservatório, dava-se partida no sistema de arraste de amônia, para que não ocorresse interrupção no processo.

O lixiviado já tratado biologicamente foi armazenado e, posteriormente, submetido ao pós-tratamento físico-químico por coagulação química-floculação-sedimentação, realizado em escala de bancada, utilizando-se o equipamento Jarteste (Nova Ética), modelo 218/LBD.

Utilizou-se o planejamento fatorial de experimentos para o delineamento dos ensaios por meio de cloreto férrico $\left(\mathrm{FeCl}_{3} \cdot 6 \mathrm{H}_{2} \mathrm{O}\right)$ como coagulante. As variáveis gradiente de velocidade média de mistura rápida (Gmr) e de floculação (Gfloc) foram fixadas em 600 (s-1) e 20 (s-1), respectivamente, em função de estudos realizados anteriormente, nos quais, por meio das análises estatísticas dos níveis testados de Gmr (entre 600 a 1.000 s-1) e Gfloc (entre 20 a 30 s-1), as diferenças não foram significativas para as respostas de DQO e cor verdadeira, com nível de significância de 5\%, adotando-se, portanto, o menor valor por razões econômicas (FELICI et al., 2010). Já o tempo de sedimentação de 6 horas foi fixado após ensaios preliminares, observando-se o tempo necessário para permitir a coleta do sobrenadante, ou seja, quando a interface de separação do lodo encontrava-se abaixo do ponto de coleta do jarro.

Desta forma, definiu-se um planejamento fatorial $2^{2}$, apresentado na Tabela 2, tendo como variáveis independentes a dosagem de cloreto férrico e o pH de coagulação química. As variáveis-respostas observadas foram DQO e cor verdadeira (após filtração em membrana de éster 
de celulose com porosidade média de 0,45 mm), de acordo com os métodos 5220 C e 2120 C, respectivamente (APHA, AWWA, WEF, 2005).

A faixa de dosagem de coagulante utilizada foi definida a partir de consultas à literatura e ensaios preliminares, enquanto que a faixa de $\mathrm{pH}$ compreendeu alguns resultados descritos na literatura por Marañón et al. (2008), Aziz et al. (2007), Ntampou et al. (2006), Wang et al. (2002) e Amokrame et al. (1997). Os valores de pH de coagulação desses trabalhos consultados variaram entre 3,8 e 5,0. Por segurança, essa faixa foi extrapolada, como mostrado na Tabela 1.

Os resultados das variáveis-respostas foram analisados utilizando-se o software STATISTICA (versão 7.0), desenvolvido pela empresa StatSoft Pacific Pty Ltd. A partir da análise dos resultados obtidos, foram identificados os fatores influentes e não influentes sobre as variáveis-respostas definidas e a sequência de planejamentos em direção à condição otimizada. Para a otimização dos processos, foram definidos novos planejamentos, considerando-se sempre o melhor resultado obtido em cada etapa como o ponto central do próximo experimento.

\section{Resultados e discussão}

A Tabela 3 apresenta a mediana dos parâmetros utilizados na caracterização do lixiviado bruto gerado no aterro do Município de Londrina ao longo de seis meses de monitoramento e após ser submetido ao processo de arraste de amônia, seguido de lodos ativados, com as respectivas porcentagens de remoção.

No desenvolvimento experimental propriamente dito, após os ajustes necessários, foram realizadas dez bateladas, cujas medianas dos parâmetros de caracterização antes e após o tratamento estão apresentadas na Tabela 3. Destaca-se que, conforme apresentado no método, o monitoramento de cada etapa de tratamento foi realizado semanalmente, com determinações de até três vezes por semana, dependendo da fase do processo.

Com base nos resultados apresentados na Tabela 3, pode-se verificar a eficiência do tratamento por stripping de amônia seguido de lodos ativados na remoção de nitrogênio amoniacal (98\%) e DBO (84\%), resultando em efluentes compatíveis com padrões de lançamento estabelecidos pela Resolução CONAMA 430/2011. No entanto, houve baixas remoções de cor verdadeira e DQO, confirmando que o lixiviado em questão apresenta baixa biodegradabilidade e elevada presença de compostos recalcitrantes, tais como substâncias húmicas, conforme reportado por Tatsi et al. (2002).

Ressalta-se, ainda, a redução da relação DBO/DQO de 0,05, no lixiviado bruto, para 0,01, no tratado, evidenciando-se, assim, o aumento de recalcitrância.

Tabela 1 - Variáveis e níveis definidos para o planejamento fatorial, utilizando-se cloreto férrico como coagulante químico.

$\begin{array}{lccc}\text { Variável } & \text { Nível mínimo (-1) } & \text { Nível médio }(0) & \begin{array}{c}\text { Nível máximo } \\ (+1)\end{array} \\ \begin{array}{l}\text { Dosagem } \\ \mathrm{Fe}^{+3}\end{array} & 300 & 500 & 700 \\ \mathrm{pH} & 3 & 4,5 & 6\end{array}$

Embora tenha ocorrido um grande consumo de alcalinidade no processo de lodos ativados (aproximadamente 56,4\%), a alcalinidade remanescente foi suficiente para manter o $\mathrm{pH}$ do lixiviado acima de 8,0.

Desse modo, os resultados apresentados revelaram a necessidade de um pós-tratamento para possibilitar a remoção de DQO e cor verdadeira. Foi, então, selecionada a técnica de coagulação-floculação-sedimentação para a remoção de compostos recalcitrantes presentes no lixiviado de aterros, representados, neste caso, pela cor verdadeira e DQO, em função da não disponibilidade do equipamento para a determinação de carbono orgânico total (COT)

\section{Resultados obtidos na coagulação-floculação- sedimentação com uso de cloreto férrico}

A Tabela 4 apresenta os resultados dos ensaios de 1 a 6 do processo de coagulação-floculação-sedimentação, utilizando-se cloreto férrico como coagulante químico e 6 horas de sedimentação.

Os melhores resultados encontrados foram relacionados às condições do ensaio 1, com dosagem de $300 \mathrm{mgFe}^{+3} / \mathrm{L}$ em pH 3,0, que alcançou 96,4\% de remoção de cor verdadeira e 80,4\% de remoção de DQO. As Figuras 1 e 2 ilustram essa situação, mostrando que os maiores valores de remoção, tanto para DQO como para cor verdadeira, foram encontrados utilizando-se dosagens menores de coagulante $\left(300 \mathrm{mgFe}^{+3} / \mathrm{L}\right.$ ) combinados com os menores valores de $\mathrm{pH}(3,0)$.

A partir desses resultados, as condições do ensaio 1 foram estabelecidas como o ponto central do próximo planejamento realizado, conforme mostrado na Tabela 5. Nessa nova etapa de experimentos, já foram considerados os pontos axiais ao planejamento, utilizados na determinação do modelo de representação dos resultados típicos dos experimentos.

Após a otimização do processo, verificou-se que os melhores resultados foram apresentados pelo ensaio 12 , como mostrado nas Figuras 3 e 4, com remoção de cor verdadeira de 98,1\% e DQO de $80,9 \%$, combinando uma dosagem de $400 \mathrm{mg} \mathrm{Fe}+3 / \mathrm{L}$ com pH 3,0. Marañón et al. (2008) também encontraram dosagem ótima de 400 $\mathrm{mg} \mathrm{Fe} \mathrm{F}^{+3} \cdot \mathrm{L}^{-1} \mathrm{com} \mathrm{pH}$ de 3,8. Resultados de remoção semelhantes aos encontrados nesse trabalho foram descritos por Castrillón et al. (2010), que utilizaram a coagulação química-floculação-sedimentação para

Tabela 2 - Matriz dos experimentos realizados inicialmente, utilizando-se cloreto férrico como coagulante químico (fatorial $2^{2}$ ).

\begin{tabular}{lcccc} 
Ensaio & \multicolumn{2}{c}{ Variável natural } & & \multicolumn{2}{c}{ Variável codificada } \\
\cline { 2 - 5 } & $\begin{array}{c}\text { Dosagem Fe } \\
\left(\mathrm{mgFe}^{+3} \cdot \mathrm{L}^{-1}\right)\end{array}$ & $\mathrm{pH}$ & $\mathrm{X}_{1}$ & $\mathrm{X}_{2}$ \\
\hline 1 & 300 & 3,0 & -1 & -1 \\
\hline 2 & 700 & 6,0 & +1 & +1 \\
3 & 700 & 3,0 & +1 & -1 \\
4 & 300 & 6,0 & -1 & +1 \\
5 & 500 & 4,5 & 0 & 0 \\
\hline 6 & 500 & 4,5 & 0 & 0
\end{tabular}

$\mathrm{X}_{1}$ : variável codificada da dosagem de $\mathrm{Fe}^{+3} ; \mathrm{X}_{2}$ : variável codificada de $\mathrm{pH}$. 
tratamento de lixiviado com uma dosagem de 1,7 g FeCl+3. $\mathrm{L}^{-1}$ e pH de 5,2, alcançando remoção de 73\% de DQO e de 98\% de cor. Amaral (2009) descreveu que os melhores resultados de remoção de cor também foram encontrados com dosagem de $400 \mathrm{mg} \mathrm{Fe} \mathrm{F}^{+3} \cdot \mathrm{L}^{-1}$ com valores de $\mathrm{pH}$ entre 4,0 e 5,0. Vale ressaltar que os resultados de eficiência do ensaio 12 foram muito próximos aos obtidos no ensaio 1 (Tabela 3), sendo necessária uma avaliação econômica para aplicações em escala real.

\section{Variável-resposta - remoção de demanda química de oxigênio}

O ensaio 12 (Tabela 5), que combinou uma dosagem de $400 \mathrm{mg} \mathrm{Fe}+3 . \mathrm{L}^{-1} \mathrm{com} \mathrm{pH} 3,0$, foi o que alcançou melhor resultado de remoção de DQO: aproximadamente $80 \%$, resultando em DQO de $433 \mathrm{mgO}_{2} \cdot \mathrm{L}^{-1}$, para a amostra filtrada, e de $488 \mathrm{mgO}_{2} \cdot \mathrm{L}^{-1}$ para a amostra não filtrada. A Figura 3 mostra a superfície de resposta para a variável remoção de DQO, considerando-se os ensaios 7 a 16 .

Um modelo matemático, apresentado na Equação 1, também foi ajustado para a variável remoção de DQO.

$y(D Q O)=79,87113-5,91657(p H)^{2}+3,92638(p H)$

$-2,14394\left(p H x D o s \mathrm{Fe}^{+3}\right)+1,84836\left(\mathrm{Dos} \mathrm{Fe}^{+3}\right)$

Esse modelo é capaz de explicar aproximadamente 98\% $\left(\mathrm{R}^{2}=0,98641\right)$ da variabilidade na porcentagem de remoção de DQO

\section{Variável-resposta - remoção de cor verdadeira}

Assim como para a variável DQO, o ensaio 12 também apresentou a maior porcentagem de remoção de cor verdadeira dentre todas as combinações, alcançando aproximadamente $98 \%$ de remoção, o que resultou em um valor absoluto de $96 \mathrm{uH}$.

Tabela 3 - Medianas dos parâmetros utilizados para caracterização do lixiviado bruto e após o tratamento por arraste de amônia seguido de lodos ativados, com as respectivas remoções, decorrentes de dez amostragens realizadas no início e no final de cada batelada.

\begin{tabular}{|c|c|c|c|c|}
\hline Parâmetros medidos & Unidade & Lixiviado bruto* & $\begin{array}{l}\text { Lixiviado tratado por stripping }+ \text { lodos } \\
\text { ativados* }\end{array}$ & \% remoção \\
\hline $\mathrm{pH}$ & - & 8,45 & 9,05 & - \\
\hline Alcalinidade & $\left(\mathrm{mgCaCO}_{3} \cdot \mathrm{L}^{-1}\right)$ & 6097 & 2661 & 56,4 \\
\hline Temperatura & ${ }^{\circ} \mathrm{C}$ & 23,0 & 26,8 & - \\
\hline Oxigênio dissolvido & $\left(\mathrm{mgO}_{2} \cdot \mathrm{L}^{-1}\right)$ & 0,52 & 0,72 & - \\
\hline Cor aparente & (Pt-Co) & 6023 & 5624 & 6,6 \\
\hline Cor verdadeira & (Pt-Co) & 5110 & 5041 & 1,4 \\
\hline $\mathrm{N}$-amoniacal & $\left(\mathrm{mgN}-\mathrm{NH}_{3} \cdot \mathrm{L}^{-1}\right)$ & 1040 & 15 & 98,5 \\
\hline NKT & $\left(\mathrm{mgN}-\mathrm{NH}_{3} \cdot \mathrm{L}^{-1}\right)$ & 1135 & 97 & 91,5 \\
\hline Nitrito & $\left(\mathrm{mgN}-\mathrm{NO}_{2} \cdot \mathrm{L}^{-1}\right)$ & 0,2 & 1,4 & - \\
\hline Nitrato & $\left(\mathrm{mgN}-\mathrm{NO}_{3} \cdot \mathrm{L}^{-1}\right)$ & 3,1 & 12,3 & - \\
\hline DBO & $\left(\mathrm{mgO}_{2} \cdot \mathrm{L}^{-1}\right)$ & 159 & 26 & 83,6 \\
\hline DQO & $\left(\mathrm{mgO}_{2} \cdot \mathrm{L}^{-1}\right)$ & 2973 & 2264 & 23,8 \\
\hline $\mathrm{DBO} / \mathrm{DQO}$ & - & 0,05 & 0,01 & 80,0 \\
\hline Sólidos totais & $\left(\mathrm{mg} \cdot \mathrm{L}^{-1}\right)$ & 7203 & 9669 & - \\
\hline Sólidos voláteis totais & $\left(\mathrm{mg} \cdot \mathrm{L}^{-1}\right)$ & 2215 & 2487 & - \\
\hline Sólidos fixos totais & $\left(\mathrm{mg} \cdot \mathrm{L}^{-1}\right)$ & 4988 & 7182 & - \\
\hline Sólidos suspensos totais & $\left(\mathrm{mg} \cdot \mathrm{L}^{-1}\right)$ & 56 & 32 & 42,8 \\
\hline Sólidos suspensos voláteis & $\left(\mathrm{mg} \cdot \mathrm{L}^{-1}\right)$ & 39 & 25 & 35,9 \\
\hline Sólidos suspensos fixos & $\left(\mathrm{mg} \cdot \mathrm{L}^{-1}\right)$ & 17 & 7 & 58,8 \\
\hline Ferro total & $\left(\mathrm{mg} \mathrm{Fe} . \mathrm{L}^{-1}\right)$ & 2,44 & 2,25 & 7,8 \\
\hline Alumínio & $\left(\mathrm{mg} \mathrm{Al} . \mathrm{L}^{-1}\right)$ & 1,82 & 1,85 & 0,0 \\
\hline Fósforo total & $\left(\mathrm{mg} \mathrm{PO}_{4} \cdot \mathrm{L}^{-1}\right)$ & 3,0 & 1,8 & 60,0 \\
\hline
\end{tabular}

*Valores representados pela mediana; DBO: demanda bioquímica de oxigênio; DQO: demanda química de oxigênio.

Tabela 4 - Resultados dos ensaios 1 a 6 após coagulação química-floculação-sedimentação, utilizando-se cloreto férrico como coagulante, conforme as variáveis e os níveis do planejamento fatorial apresentado na Tabela 1.

\begin{tabular}{|c|c|c|c|c|c|c|}
\hline \multirow[b]{2}{*}{ Ensaio } & \multicolumn{2}{|c|}{ Variável natural } & \multicolumn{4}{|c|}{ Variável-resposta } \\
\hline & Dosagem Fe $\left(\mathrm{mgFe}^{+3} \cdot \mathrm{L}^{-1}\right)$ & $\mathrm{pH}$ & \% remoção cor verdadeira & \% remoção DQO & Cor verdadeira $(\mathrm{uH})$ & $\begin{array}{c}\mathrm{DQO} \\
\left(\mathrm{mgO}_{2} \mathrm{LL}^{-1}\right)\end{array}$ \\
\hline 1 & 300 & 3,0 & 96,4 & 80,4 & 180 & 442 \\
\hline 2 & 700 & 6,0 & 90,7 & 65,8 & 466 & 774 \\
\hline 3 & 700 & 3,0 & 10,8 & 72,6 & 4497 & 620 \\
\hline 4 & 300 & 6,0 & 81,4 & 53,7 & 938 & 1048 \\
\hline 5 & 500 & 4,5 & 95,6 & 79,6 & 222 & 462 \\
\hline 6 & 500 & 4,5 & 95,7 & 79,5 & 218 & 464 \\
\hline
\end{tabular}


A Figura 4 mostra a superfície de resposta para a variável remoção de cor verdadeira, considerando-se o planejamento otimizado, compreendendo-se os ensaios 7 a 16.

Novamente, ajustou-se um modelo quadrático aos dados experimentais obtidos, obtendo-se uma equação polinomial de segunda ordem, que representa os resultados de remoção de cor verdadeira e é expressa na Equação 2

$y($ Cor Verd $)=97,02632+5,00229(p H)-4,62464(p H)^{2}$

O modelo encontrado é capaz de explicar $88 \%\left(R^{2}=0,88879\right)$ da variabilidade na porcentagem de remoção de cor verdadeira.

\section{Avaliação do modelo estatístico}

As superfícies de resposta obtidas estabeleceram o ponto de máxima remoção das variáveis-resposta, como pode ser observado nas Figuras 3 e 4.

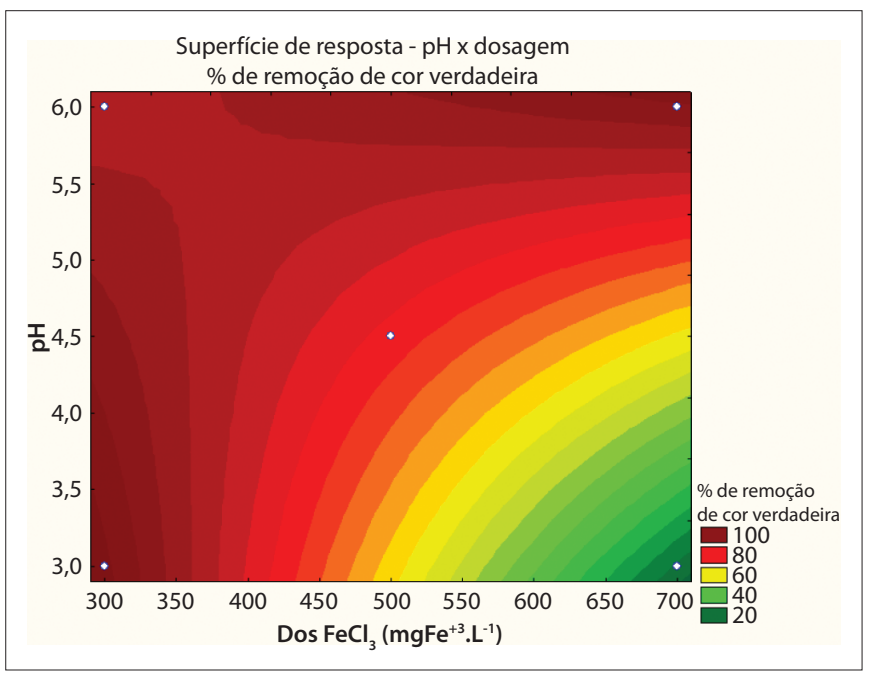

Figura 1 - Superfície de resposta para resultados de remoção de cor verdadeira dos ensaios 1 a 6 após coagulação química-floculaçãosedimentação, utilizando-se cloreto férrico como coagulante.
Dessa forma, levando-se em consideração as afirmações de Montgomery e Runger (2003) de que, se derivando um modelo estatístico, é possível encontrar suas raízes e, assim, determinar as condições que possam maximizar as variáveis-respostas, podem-se encontrar as raízes dos modelos para fazer sua checagem.

Durante o trabalho, foram observadas duas variáveis-respostas, DQO e cor verdadeira. Contudo, para a verificação dos modelos, escolheu-se derivar apenas o modelo obtido para a variável DQO, com $R^{2}=0,98641$, visto ser a característica de maior interesse por estar relacionada à matéria orgânica recalcitrante, que foi o objetivo estabelecido. Em trabalhos anteriores, observou-se que há uma correlação direta entre a remoção de DQO e a cor. Para o $\mathrm{pH}$, o valor codificado da raiz foi de 0,84 , que, na faixa estudada, corresponde ao $\mathrm{pH}$ de 3,6. Já para a dosagem, o valor codificado da raiz corresponde a $-2,8$. Contudo, esse valor está fora da faixa estudada, que vai até $-1,4(\sqrt{2})$. Assim, definiram-se mais 3 ensaios, com o ponto limite da faixa estudada, a raiz encontrada e o ponto

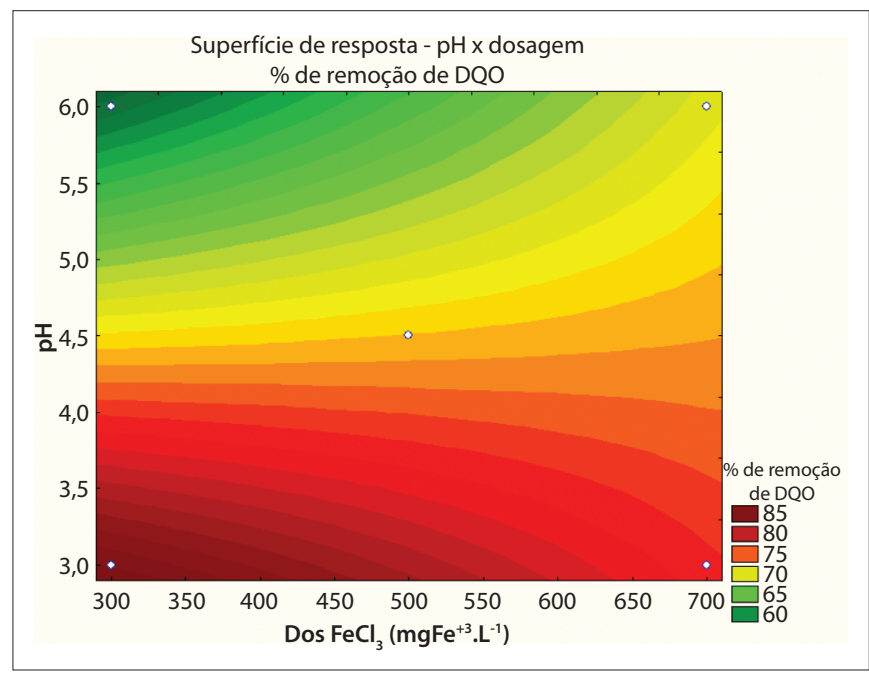

Figura 2 - Superfície de resposta para resultados de remoção de demanda química de oxigênio (DQ0) dos ensaios 1 a 6 após coagulação químicafloculação-sedimentação, utilizando-se cloreto férrico como coagulante.

Tabela 5 - Resultados dos ensaios 7 a 16 após coagulação química-floculação-sedimentação, utilizando-se cloreto férrico como coagulante e considerando-se os pontos axiais.

\begin{tabular}{|c|c|c|c|c|c|c|}
\hline \multirow[b]{2}{*}{ Ensaio } & \multicolumn{2}{|c|}{ Variável natural } & \multicolumn{4}{|c|}{ Variável-resposta } \\
\hline & Dosagem Fe (mgFe $\left.{ }^{+3} / \mathrm{L}\right)$ & $\mathrm{pH}$ & \% remoção cor verdadeira & \% remoção DQO & Cor verdadeira $(\mathrm{uH})$ & $\begin{array}{c}\mathrm{DQO} \\
\left(\mathrm{mgO}_{2} / \mathrm{L}\right)\end{array}$ \\
\hline 7 & 229,3 & 2,3 & 91,1 & 65,8 & 447 & 774 \\
\hline 8 & 229,3 & 3,7 & 97,1 & 77,7 & 145 & 505 \\
\hline 9 & 370,7 & 2,3 & 89,2 & 74,9 & 545 & 569 \\
\hline 10 & 370,7 & 3,7 & 97,7 & 78,1 & 115 & 495 \\
\hline 11 & 200,0 & 3,0 & 93,9 & 77,1 & 309 & 518 \\
\hline 12 & 400,0 & 3,0 & 98,1 & 80,9 & 96 & 433 \\
\hline 13 & 300,0 & 2,0 & 77,4 & 62,1 & 1140 & 858 \\
\hline 14 & 300,0 & 4,0 & 95,4 & 73,6 & 232 & 597 \\
\hline 15 & 300,0 & 3,0 & 96,4 & 80,4 & 180 & 443 \\
\hline 16 & 300,0 & 3,0 & 96,9 & 80,7 & 155 & 437 \\
\hline
\end{tabular}

DQO: demanda química de oxigênio. 
médio entre elas, todos combinados com valor de $\mathrm{pH}$ de 3,6, como mostrado na Tabela 6.

É válido ressaltar que, todas as vezes em que foram extrapoladas as faixas das variáveis estudadas, as porcentagens de remoção das variáveis respostas foram prejudicadas, como é o caso, por exemplo, do ensaio 17. Dessa forma, torna-se evidente a dependência do modelo à faixa definida e estudada, em que possíveis extrapolações podem levar a erros e incredibilidade do modelo estatístico.

Os resultados do experimento 19, alcançados por meio de uma combinação conduzida pelas raízes obtidas do modelo, mostraram elevadas remoções de cor verdadeira e DQO, semelhantes aos resultados obtidos no ensaio 12 (remoção de cor verdadeira de $98,1 \%$ e remoção de DQO de 80,9\%), ponto de maior remoção encontrado entre todas as combinações estudadas. Pode-se dizer, assim, que o modelo encontrado foi capaz de mostrar uma boa tendência das variáveis respostas, buscando sempre maximizar a eficiência do tratamento.

Realizou-se, então, um teste estatístico denominado t-test, com nível de significância de 5\% ( $\mathrm{p}<0,05)$, buscando avaliar a existência de diferença significativa entre os resultados dos ensaios 12 e 19. A análise estatística demonstrou que existe diferença significativa paras a variáveis-respostas cor verdadeira e DQO para os resultados obtidos com os referidos ensaios.

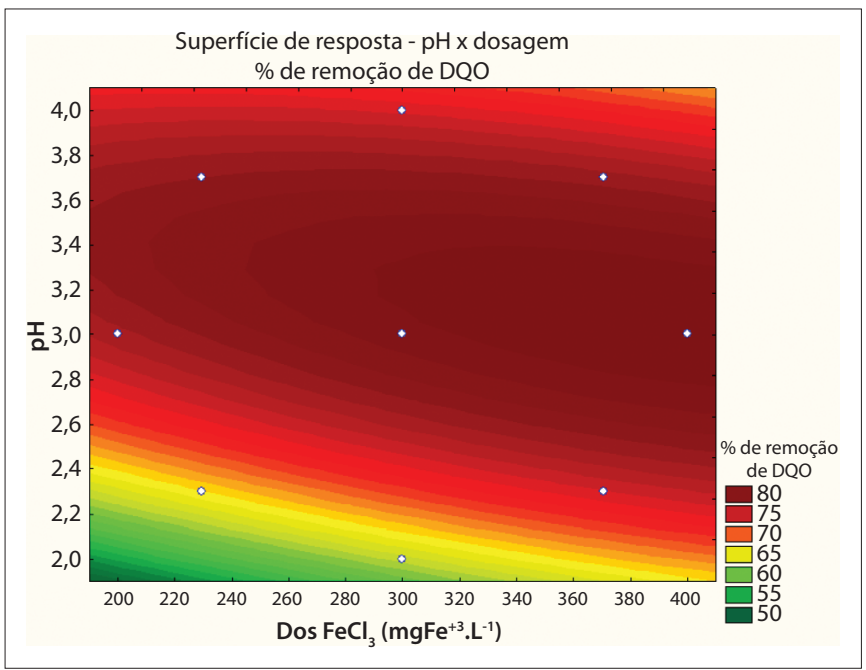

Figura 3 - Gráfico de superfície-resposta dos ensaios 7 a 16 para remoção de demanda química de oxigênio (DQO) em função da variação de $\mathrm{pH}$ e dosagem de cloreto férrico.
Assim, definiu-se o ensaio 12 (dosagem: $400 \mathrm{mg} \mathrm{Fe}^{+3} / \mathrm{L}$; pH: 3,0) como o melhor ponto entre todas as combinações testadas com o coagulante cloreto férrico. É importante ressaltar que, mesmo existindo diferença significativa para as variáveis-respostas cor verdadeira e DQO nos ensaios 12 e 19, os resultados do ensaio 19 (dosagem: $200 \mathrm{mg} \mathrm{Fe} \mathrm{e}^{+3} . \mathrm{L}^{-1} ; \mathrm{pH}$ : 3,6) devem também ser considerados em aplicações práticas, devido, principalmente, à redução de 50\% na dosagem de coagulante e ao pH mais elevado em comparação ao ensaio 12.

\section{Comparação entre demanda química de oxigênio de amostras filtradas e não filtradas}

Para comparar e verificar a influência dos sólidos em suspensão na determinação da DQO, as determinações a partir do ensaio 7 (otimização do processo) também foram conduzidas sem a filtração da amostra, como mostrado na Tabela 7 .

Os resultados mostraram pequenas diferenças entre as porcentagens de remoção da DQO das amostras filtradas e não filtradas, evidenciando a possibilidade de determinação da DQO sem necessidade de filtração prévia das amostras.

Para confirmar essa observação, foi realizado o t-test com nível de significância de 5\%, conforme descrito anteriormente, o qual

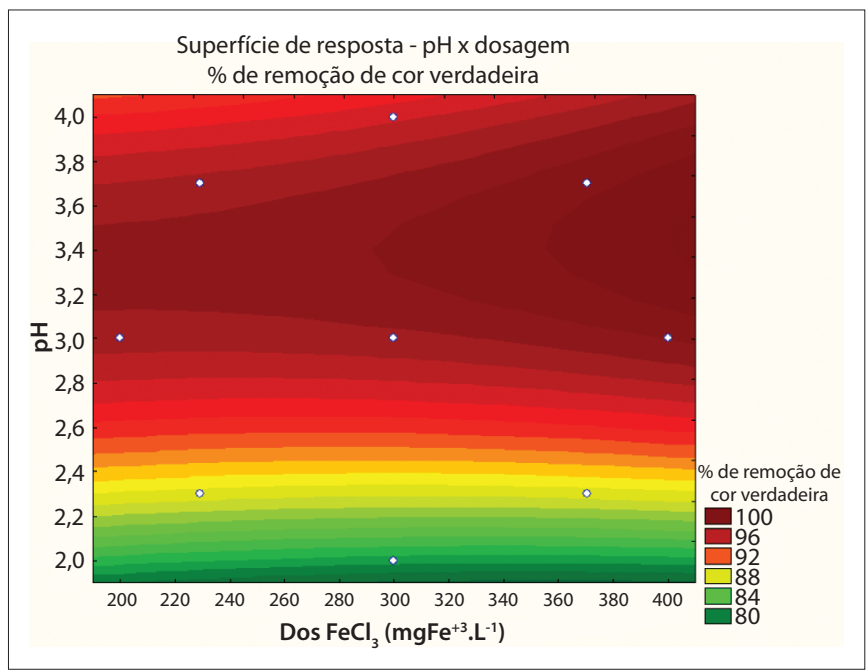

Figura 4 - Gráfico de superfície-resposta dos ensaios 7 a 16 para remoção de cor verdadeira em função da variação de $\mathrm{pH}$ e dosagem de cloreto férrico.

Tabela 6 - Resultados dos experimentos realizados com as raízes do modelo estatístico da remoção de DQO após coagulação química-floculaçãosedimentação, utilizando-se cloreto férrico como coagulante.

\begin{tabular}{lccccccc} 
& \multicolumn{2}{c}{ Variável natural } & & \multicolumn{4}{c}{ Variável-resposta } \\
Ensaio & Dosagem Fe $\left(\mathrm{mgFe}^{+3} \cdot \mathrm{L}^{-1}\right)$ & $\mathrm{pH}$ & \% remoção cor verdadeira & \% remoção DQO & Cor verdadeira $(\mathrm{uH})$ & $\begin{array}{c}\mathrm{DQO} \\
\left(\mathrm{mgO} \cdot \mathrm{L}^{-1}\right)\end{array}$ \\
\hline 17 & 100 & 3,6 & 88,2 & 70,6 & 595 & 666 \\
18 & 150 & 3,6 & 93,1 & 78,9 & 347 & 478 \\
19 & 200 & 3,6 & 94,3 & 79,1 & 288 & 474 \\
\hline
\end{tabular}

DQO: demanda química de oxigênio. 
comprovou não haver diferença significativa entre os resultados de DQO das amostras filtradas e não filtradas.

Esses resultados comprovam também que os valores de remoção de DQO estão diretamente relacionados à eficiência do processo e não sofreram interferências da filtração das amostras.

\section{Ferro residual}

Segundo o artigo 34 da Resolução 357/2005 do CONAMA, o valor máximo de ferro total dissolvido permissível para o lançamento de efluentes em corpos d'agua é de $15 \mathrm{mgFe} . \mathrm{L}^{-1}$.

Os resultados de ferro residual dissolvido nos efluentes após tratamento por coagulação química-floculação-sedimentação, utilizando-se como coagulante o cloreto férrico, produzidos nos ensaios 1 a 19, são apresentados na Tabela 8.

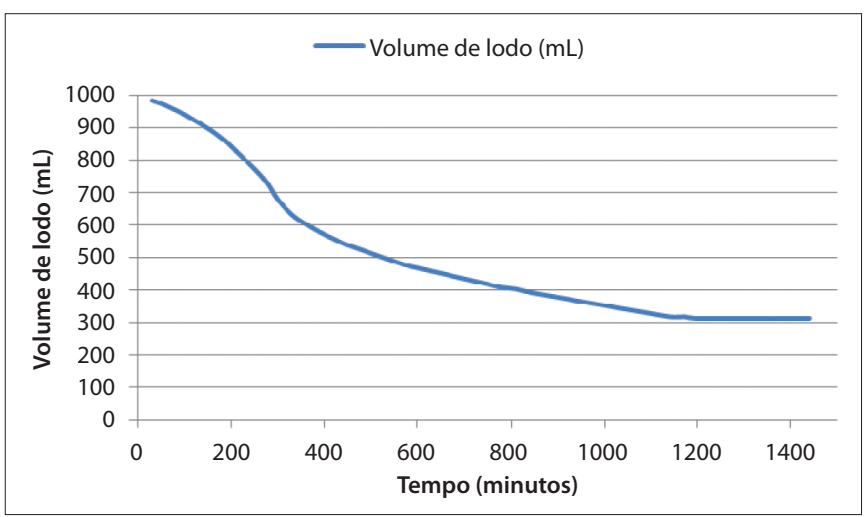

Figura 5 - Curva de clarificação/adensamento do lodo produzido após coagulação química-floculação-sedimentação utilizando-se cloreto férrico como coagulante, para as condições do ensaio 12 (dosagem: $400 \mathrm{mgFe} \mathrm{e}^{+3} \cdot \mathrm{L}^{-1}$ e $\left.\mathrm{pH} 3,0\right)$.

Tabela 7 - Comparação dos valores de DQO das amostras filtrada e não filtrada.

\begin{tabular}{lcccc}
\multirow{2}{*}{ Ensaio } & \multicolumn{2}{c}{$\mathrm{DQO}_{\text {da amostra filtrada }}$} & \multicolumn{3}{c}{$\mathrm{DQO}$ da amostra não filtrada } \\
\cline { 2 - 5 } & $\mathrm{mgO}_{2} / \mathrm{L}$ & $\%$ remoção & $\mathrm{mgO}_{2} / \mathrm{L}$ & $\%$ remoção \\
\hline 7 & 774 & 65,8 & 802 & 65,7 \\
\hline 8 & 505 & 77,7 & 520 & 77,7 \\
\hline 9 & 569 & 74,9 & 587 & 74,9 \\
\hline 10 & 495 & 78,1 & 514 & 78,0 \\
\hline 11 & 518 & 77,1 & 530 & 77,3 \\
\hline 12 & 433 & 80,9 & 448 & 80,8 \\
\hline 13 & 858 & 62,1 & 913 & 60,9 \\
\hline 14 & 597 & 73,6 & 614 & 73,7 \\
\hline 15 & 443 & 80,4 & 468 & 80,0 \\
\hline 16 & 437 & 80,7 & 462 & 80,2 \\
\hline 17 & 665,6 & 70,6 & 707 & 69,7 \\
\hline 18 & 478,3 & 78,9 & 487 & 79,2 \\
\hline 19 & 474,2 & 79,1 & 485 & 79,3 \\
\hline 20 & 443,9 & 80,4 & 456,4 & 80,5 \\
\hline 21 & 438,6 & 80,6 & 448,1 & 80,8 \\
\hline 22 & 431,4 & 80,9 & 440,0 & 81,2 \\
\hline
\end{tabular}

DQO: demanda química de oxigênio.
Alguns ensaios apresentaram concentrações de ferro dissolvido residual acima do valor permissível para lançamento (15 mg. $\left.\mathrm{L}^{-1}\right)$, de acordo com a Resolução CONAMA 430/11. Isso pode estar relacionado à utilização de elevadas dosagens de coagulante nos experimentos.

O ensaio 12, no qual foram encontradas as maiores eficiências de remoção de cor verdadeira e DQO, também extrapolou os limites permissíveis preconizados pela legislação. Por outro lado, deve-se considerar que, visando à possibilidade de descarte desse efluente, a elevação do pH pode contribuir para a redução dessas concentrações, devido à precipitação.

\section{Curva de sedimentação do lodo}

Outro fato importante a ser destacado neste trabalho foi a dificuldade encontrada na sedimentação do lodo, que, na grande maioria dos ensaios, apresentou-se muito lenta.

Nesse sentido, após a definição do ponto de melhor resultado de remoção de cor verdadeira e DQO, foi construída uma curva de clarificação/adensamento do lodo para as condições do ensaio 12 , conforme a Figura 5.

Pôde-se perceber que o lodo sedimentou muito lentamente, demorando por volta de 20 horas para estabilizar, o que pode tornar o processo inviável quando aplicado em escala real.

Marañón et al. (2008) e Amaral (2009) também descreveram que a sedimentação dos flocos formados foi muito lenta e utilizaram em seus estudos um tempo de sedimentação de 24 horas.

A velocidade de sedimentação do lodo foi de $0,0428 \mathrm{~cm} / \mathrm{min}$. Após 20 horas de sedimentação, o volume de lodo produzido foi de

Tabela 8 - Ferro residual dissolvido nos efluentes após coagulação química-floculação-sedimentação, utilizando-se cloreto férrico como coagulante.

\begin{tabular}{lccc} 
Ensaio & $\begin{array}{c}\text { Dosagem } \\
\left(\mathrm{mgFe}^{+3} \cdot \mathrm{L}^{-1}\right)\end{array}$ & $\mathrm{pH}$ & $\begin{array}{c}\text { Ferro residual dissol- } \\
\text { vido } \\
\left(\mathrm{mgFe}^{-1}\right)\end{array}$ \\
\hline 1 & 300 & 3,0 & 20,01 \\
2 & 700 & 6,0 & $\mathrm{ND}$ \\
3 & 700 & 3,0 & 53,79 \\
\hline 4 & 300 & 6,0 & $\mathrm{ND}$ \\
\hline 5 & 500 & 4,5 & 0,77 \\
\hline 6 & 500 & 4,5 & 0,59 \\
\hline 7 & 229,3 & 2,3 & 53,36 \\
\hline 8 & 229,3 & 3,7 & 1,93 \\
\hline 9 & 370,7 & 2,3 & 22,08 \\
\hline 10 & 370,7 & 3,7 & 0,96 \\
\hline 11 & 200 & 3,0 & 24,88 \\
\hline 12 & 400 & 3,0 & 25,26 \\
\hline 13 & 300 & 2,0 & 26,71 \\
\hline 14 & 300 & 4,0 & 1,97 \\
15 & 300 & 3,0 & 0,69 \\
\hline 16 & 300 & 3,0 & 1,28 \\
\hline 17 & 100 & 3,6 & 17,15 \\
\hline 18 & 150 & 3,6 & 20,09 \\
\hline 19 & 200 & 3,6 & 19,89 \\
\hline
\end{tabular}

ND: não detectável. 
$300 \mathrm{~mL}$ por litro, com umidade média de 74\%. A adição de um polieletrólito ao processo pode facilitar a sedimentação do lodo, fazendo com que essa operação ocorra mais rapidamente.

\section{Conclusões}

Concluiu-se que a técnica de coagulação-floculação-sedimentação com $\mathrm{FeCl}_{3} \cdot 6 \mathrm{H}_{2} \mathrm{O}$ como coagulante é eficiente para o pós-tratamento de lixiviado de aterro, pois foi capaz de remover $98,1 \%$ de cor verdadeira e $80,9 \%$ de DQO, com uma dosagem de $400 \mathrm{mgFe}^{+3}$. $\mathrm{L}^{-1}$ e $\mathrm{pH}$ de 3,0 .

Observou-se que os pontos de melhores remoções foram os mesmos, tanto para a DQO quanto para a cor verdadeira, evidenciando que os altos teores desses parâmetros encontrados no lixiviado devem ser causados pela mesma "fonte", como as substâncias húmicas.

Ressalta-se, ainda, que a sedimentação do lodo foi muito lenta, devido à baixa velocidade de sedimentação das partículas. Para o ponto de melhor resultado alcançado na remoção da cor verdadeira e da DQO, o lodo demorou cerca de 20 horas para estabilizar o regime de sedimentação. No entanto, isso pode ser resolvido com a utilização de um auxiliar de sedimentação, como os polieletrólitos, o que já foi realizado e divulgado por Castro et al. (2012) com esse mesmo lixiviado, podendo-se reduzir as dosagens de coagulante (de 400 para $300 \mathrm{mgFe}^{+3} \cdot \mathrm{L}^{-1}$ ), de acidificante (de pH 3,0 para 3,5) e o tempo de sedimentação de 6 horas para 30 minutos durante a execução do experimento e de 20 horas para 1 hora e 30 minutos, na estabilização do regime de sedimentação.

\section{Referências}

AMARAL, M.S. (2009) Tratamento físico-químico de lixiviado de aterro sanitário pré-tratado por processo biológico aeróbio. Dissertação (Mestrado em Engenharia) -Universidade de São Paulo, São Paulo.

AMERICAN PUBLIC HEALTH ASSOCIATION; AMERICAN WATER WORKS ASSOCIATION; WATER ENVIRONMENT FEDERATION (APHA; AWWA; WEF) (2005). Standard methods for the examination of water $e$ wastewater, $21^{\text {st }}$ ed. Washington DC: APHA, AWWA, WEF.

AMOKRANE, A.; COMEL, C.; VERON, J. (1997) Landfill leachate pretreatment by coagulation-flocculation. Water Resources, v. 31, n. 11, p. 2775-2782.

AZIZ, H.A.; ALIAS, S.; ADLAN, M.N.; FARIDAH, A.H.; ZAHARI, M.S.M. (2007) Colour removal from landfill leachate by coagulation and flocculation processes. Bioresource Technology, v. 98, p. 218-220.

CASTILHOS JUNIOR, A.B. (org). (2006) Gerenciamento de resíduos sólidos urbanos com ênfase na proteção de corpos d'água: prevenção, geração e tratamento de lixiviados de aterros sanitários. Rio de Janeiro: ABES. (Projeto PROSAB).

CASTRILLÓN, L.; FERNÁNDEZ-NAVA, Y.; ULMANU, M.; ANGER, I.; MARAÑÓN, E. Physico-chemical and biological treatment of MSW landfill leachate. Waste Management, v. 30. p. 228-235, 2010.

CASTRO, A.P.; YAMASHITA, F.; SILVA, S.M.C.P. (2012) Adição de polieletrólito ao processo de floculação no pós-tratamento de lixiviado por coagulação-floculação-sedimentação. Revista Engenharia Sanitária e Ambiental, v. 17 n. 1, p. 25-32.

DI BERNARDO, L.\& DANTAS, A.D. (2005) Métodos e técnicas de tratamento de água. 2. ed. Rio de Janeiro: ABES; RiMa. v. 1.

FELICI, E.M.; SILVA, S.M.C.P.; KURODA, E.K.; BATISTA, G.A. (2010). Fatores que podem exercer efeitos significativos na remoção de DQO de processo de pós-tratamento de chorume utilizando processo físico-quimico. In: Simpósio Ítalo-Brasileiro de Engenharia Sanitária e Ambiental, 10 Anais... Maceió: Sibesa, 2010, v. 1.
KURNIAWAN, T.A.; WAI-HUNG, L.; CHAN, Y.S.G. (2006) Physicochemical treatments for removal of recalcitrant contaminants from landfill leachate. Journal of Hazardous Materials, v. B129, p. 80-100.

MARAÑÓN, E.; CASTRILLÓN, L.; FERNÁNDEZ-NAVA, Y.; FERNÁNDEZ MÉNDEZ, A.; FERNÁNDEZ-SÁNCHEZ, A. (2008) Coagulationflocculation as a pretreatment process at a landfill leachate nitrificationdenitrification plant. Journal of Hazardous Materials, v. 156, p. 538-544.

MONTGOMERY, C. D.; RUNGER, G. C. Estatística aplicada e probabilidade para engenheiros. 2.ed. São Paulo: LTC, 2003.

NTAMPOU, X.; ZOUBOULIS, A.I.; SAMARAS, P. (2006) Appropriate combination of physico-chemical methods (coagulation/flocculation and ozonation) for the efficient treatment of landfill leachates. Chemosphere, v. 62, p. $722-730$.

OZTURK, I.; ALTINBAS, M.; KOYUNCU, I.; ARIKAN, O.; GOMEC-YANGIN, C. (2003) Advanced physico-chemical treatment experiences on young municipal landfill leachates. Waste Management, v. 23, p. 441-446.

TATSI, A.A; ZOUBOULIS, A.I A field investigation of the quantity and quality of leachate from a municipal solid waste landfill in a Mediterranean climate (Thessaloniki, Greece). Advances in Environmental Research, v. 6, p. 207-219, 2002.

WANG, Z.P.; ZHANG, Z.; LIN, Y.J.; DENG, N.S.; TAO, T.; ZHUO, K. (2002) Landfill leachate treatment by a coagulation-photooxidation process. Journal of Hazardous Materials, v. 95, n. 1-2, p. 153-159.

WISZNIOWSKI, J.; ROBERT, D.; SURMACZ-GORSKA, J.; MIKSCH, K.; WEBER, J.V. (2006) Landfill leachate treatment methods: a review. Environmental Chemistry Letters, v. 4, p. 51-61.

ZOUBOULIS, A.I.; CHAI, X.L.; KATSOYIANNIS, I.A. (2004) The application of bioflocculant for the removal of humic acids from stabilized landfill leachates. Journal of Environmental Management, v. 70, p. 35-41. 